DFGV EAESP

CENTRO DE ESTUDOS

EM PLANEJAMENTO

E GESTÃO DE SAÚDE
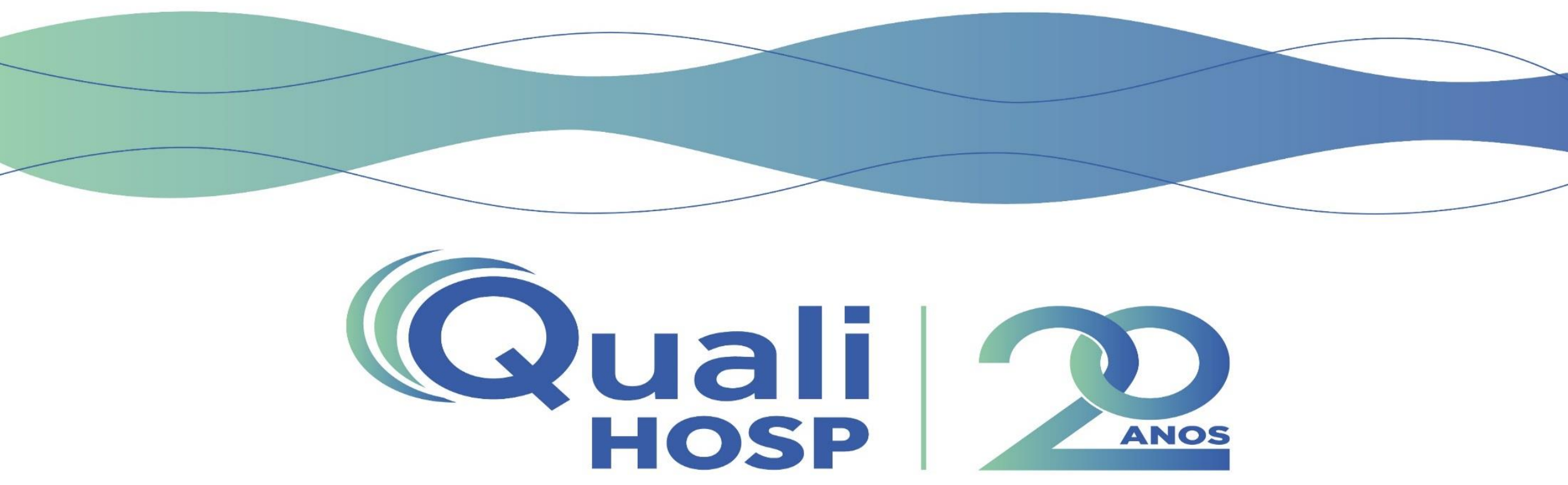

TO ERR IS HUMAN: 20 ANOS EM AÇÃO

\title{
IMPLANTAÇÃO DA EQUIPE DE REFERÊNCIA EM UMA UNIDADE DE ATENDIMENTO INTEGRADO (UAI) NA CIDADE DE UBERLÂNDIA
}

Autores: Cristiane Aparecida Betta, Elizabeth Akemi Nishio, Fabiana Yassuko, Maria Aparecida Gonçalves Gomes, Paula Dal Maso Altimari e Vanessa Ceravolo Gurgel Silva 


\section{IMPLANTAÇÃO DA EQUIPE DE REFERÊNCIA EM UMA UNIDADE DE ATENDIMENTO INTEGRADO (UAI) NA CIDADE DE UBERLÂNDIA}
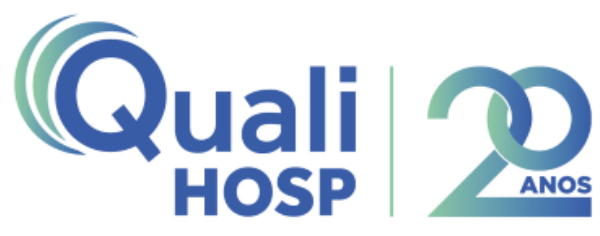

INTRODUÇÃO: Os serviços de urgência são uma das principais portas de entrada do paciente no SUS. O Ministério da Saúde preconizou para estes serviços a utilização de protocolo de classificação de risco;

Uberlândia: Município do Estado de Minas Gerais População: 683.247 (IBGE, 2018)

UAl: 08

ESF: 74

UBS: 08

Hospital Municipal: 01

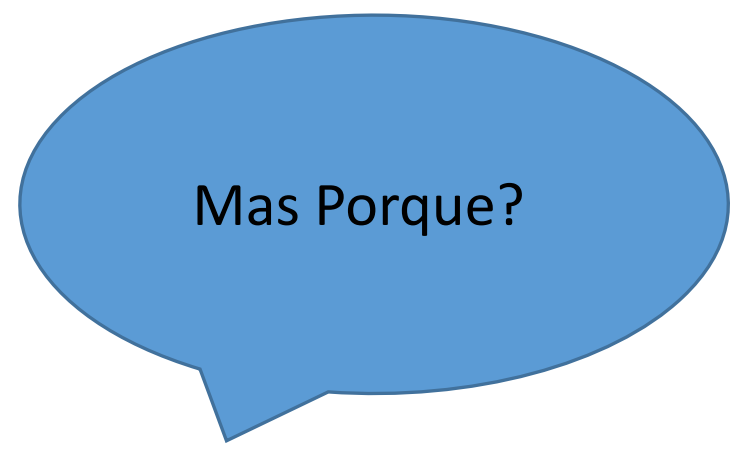

Hospital Universitário: 01

OBJETIVO: Analisar os tempos de atendimento-desfecho da equipe médica e de enfermagem em serviços de urgência e emergência antes e após a implantação da equipe de referência.

MÉTODO: Estudo retrospectivo, documental, quantitativo

PROTOCOLO UTILIZADO PARA CLASSIFICAÇÃO DE RISCO: Manchester 


\section{FLUXO DE ATENDIMENTO DOS PACIENTES COM A EQUIPE DE REFERÊNCIA}

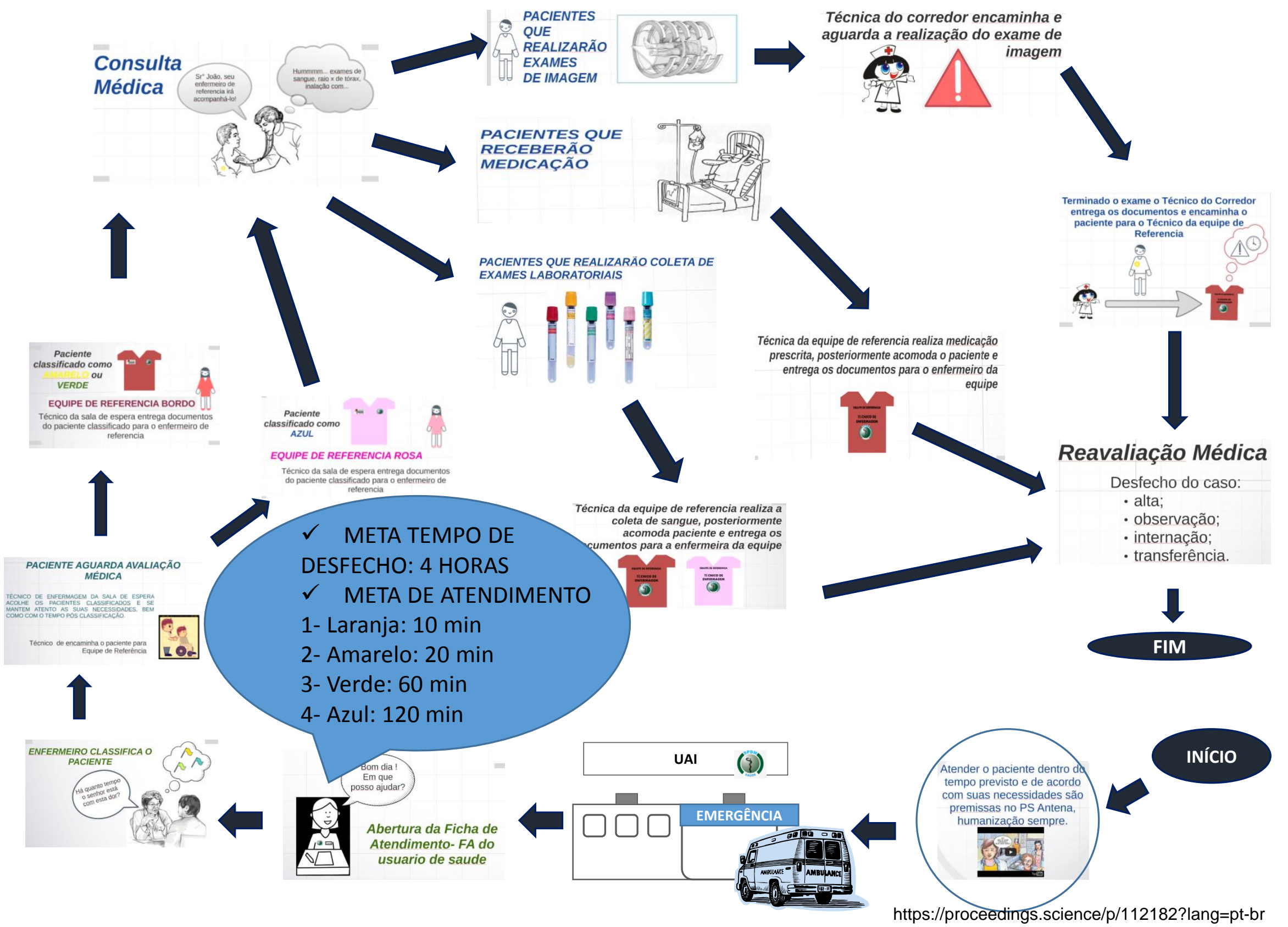




\section{RESULTADOS}

\section{Quali

MÉDIA TEMPO ENTRE ABERTURA

FICHA E CLASSIFICAÇÃO(min)

Média de atendimento da UAl= 12.480 mês Média de atendimento diário=416

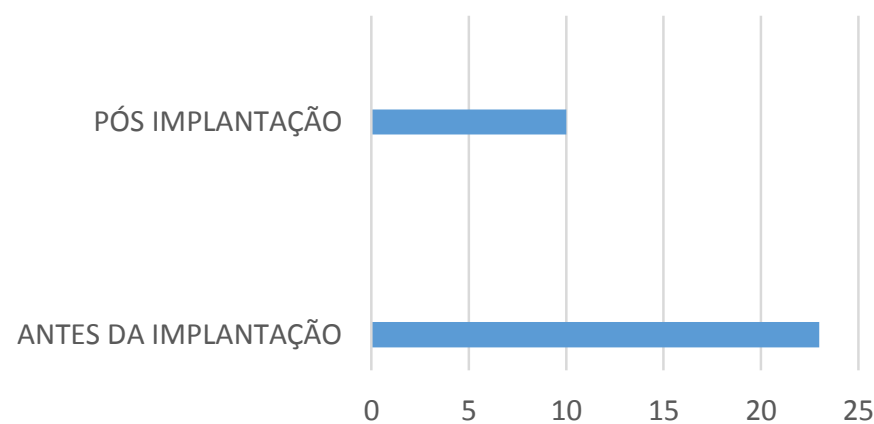

MÉDIA DE TEMPO ENTRE CLASSIFICAÇÃO E ATENDIMENTO AMARELO

MÉDIA TEMPO ENTRE CLASSIFICAÇÃO E ATENDIMENTO LARANJA

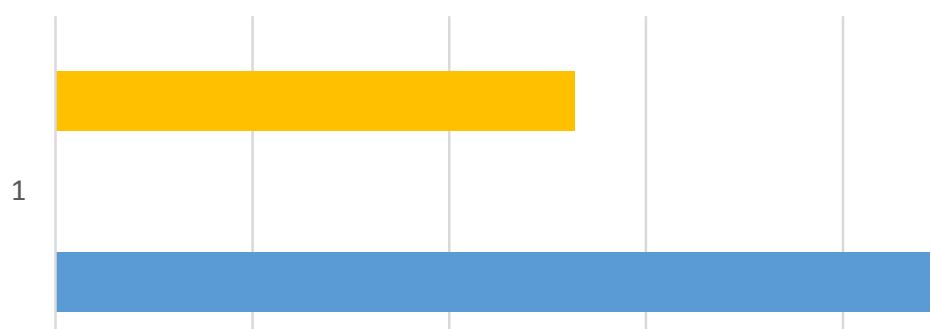




\section{RESULTADOS}

\section{Quali $\mid$ Pos}

MÉDIA TEMPO ENTRE CLASSIFICAÇÃO

E ATENDIMC
MÉDIA TEMPO ENTRE CLASSIFICAÇÃO E

TO AZUL

$\checkmark$ Redução de $50 \%$ no tempo de espera para classificação de risco

00:00 00:14

$00: 28$ - PÓS IMPLANTAÇÃO

$\checkmark$ Redução de $57 \%$ no tempo de espera entre a consulta e a

01:12 01:26 01:40 01:55 ANTES DA IMPLANTAÇÃO

RTURA DA FICHAE CASOS

$02: 24$

$01: 12$

00:00 medicação

TEMPO ME

$\checkmark$ Redução de $55 \%$ no tempo de desfecho

- MÉDIA DE TEMPO DE DEST 


\section{PERCEPÇÃO DO PACIENTE}

"O Uberlândia Esporte Clube agradece aos profissionais da UAI Tibery pela agilidade e Qualidade no atendimento ao nosso treinador..."

"O Atendimento na UAI Melhorou muito"

\section{Referências:}

Ministério da Saúde (BR). Acolhimento e calssificação de risco nos serviços de saúde. Brasília, Ministério da Saúde. 2009. http://www.saude.mg.gov.br/cer/page/466-classificacao-de-risco-sesmg Silva, V.C.G; Hayashi,A.A.L; Nishio,E.A; Fernandes,I.R; Mansur,N.S. Implantação de equipes de referência num pronto socorro municipal . Revista Ciência \& Saberes ReonFacema.2016 Jul-Set; 2(3):232-237

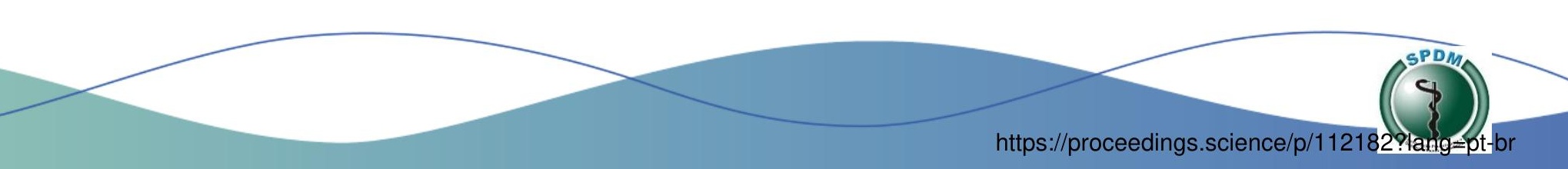

